\title{
White forelock with malformations
}

INSERM

\section{Source}

INSERM. (1999). Orphanet: an online rare disease and orphan drug data base. White forelock with malformations. ORPHA:2475

White forelock with malformations is a multiple congenital anomalies syndrome characterized by poliosis, distinct facial features (epicanthal folds, hypertelorism, posterior rotation of ears, prominent philtrum, high-arched palate) and congenital anomalies/malformations of the eye (blue sclera), cardiopulmonary (atrial septal defect, prominent thoracic and abdominal veins), and skeletal (clinodactyly, syndactyly of the fingers and 2 nd and 3 rd toes) systems. There have been no further descriptions in the literature since 1980. 